\title{
Accommodating urban freight in city planning
}

\author{
Ivan Sanchez-Diaz ${ }^{1 *}$ and Michael Browne ${ }^{2}$
}

Research related to the implications of urbanization are gaining increasing relevance as more than half of the world's population already live in urban environments, and this trend is expected to continue so that by 2030 two thirds of the population will live in cities. Urbanization has proved to bring many benefits in terms of resource efficiency, economic development and an increased access to services and goods. However, densely populated cities where multiple users compete for public space also bring about multiple challenges for livability and, in general, for sustainability. Coping with these challenges require an understanding of the personal and goods mobility needs that such a growth entails, and the ability to plan accordingly. Urban planning has traditionally focused on alleviating personal mobility challenges with the aim of having more efficient and sustainable transportation systems. For instance, the European Commission has promoted the concept of Sustainable Urban Mobility Plans (SUMP) that integrates functional areas and considers the perspectives of multiple stakeholders to allow cities to reach the sustainability goals intended by the EU [8].

Although freight plays an important part in city dynamics, i.e. freight vehicles represent about $20-30 \%$ of vehicle miles traveled and are responsible for $16-50 \%$ of the environmental emissions $[2,6]$ - most of the SUMPs being developed do not include detailed plans on how to accommodate urban freight into city plans. Incorporating urban freight into city plans require detailed studies about the interaction between freight flows and the urban environment, as well as on how to integrate freight stakeholders' interests in planning. This Topical Collection (TC) seeks to provide a better scientific foundation for the integration of freight into city planning. To this effect, this issue assembles research results related to Accommodating Urban Freight in City Planning from various perspectives and geographic contexts. This TC contains the best papers presented at the Volvo Research and Educational Foundations (VREF) Conference

* Correspondence: ivan.sanchez@chalmers.se

${ }^{1}$ Chalmers University of Technology, Gothenburg, Sweden

Full list of author information is available at the end of the article on Urban Freight organized in Gothenburg on October $17-19,2016$, but the call for papers was open to external submissions as well.

This TC contains 10 papers that present the experience in various cities including the case of Rome in Italy, Västra Götaland, Malmö and Stockholm in Sweden, Bergen and Trondheim in Norway, Odense and Copenhagen among others in Denmark, Brussels and Antwerp in Belgium, London and Newcastle among others in the UK, Singapore, Troy and New York in the USA, and Medellin in Colombia. This TC covers different dimensions of planning. Dalla Chiara and Cheah [7], Campbell et al. [5], Pitera et al. [13] and Aditjandra and Zunder [1] focus on planning related to local freight needs; Palacios-Argüello et al. [12], Gonzalez-Calderon et al. [10] and Fossheim and Andersen [9] study the characteristics and requirements of planning for freight in metropolitan areas; Buldeo Rai et al. [4] and Arnold et al. [3] focus on innovations related to urban freight, while Le Pira et al. [11] study the interaction between freight stakeholders when finding a policy package in common agreement.

\section{Planning for local freight needs}

Dalla Chiara and Cheah [7] study the demand for parking in urban areas with a high intensity of freight deliveries in Singapore. The authors analyze parking activity data collected using video-recordings at two malls (considering arrival rates, statistical distributions of parking duration, waiting time in queues and driver parking location choice) and study freight vehicles parking using queueing theory. The results reveal a poor performance illustrated by the long queuing times and numerous illegal parking that have negative impacts on supply chains and on citizens. The authors conclude that under these conditions urban freight policy, such as, off-peak deliveries or centralized receiving stations can be effective in solving current congestion issues.

Campbell et al. [5] assess parking demand from freight and service vehicles and study the role of freight demand management initiatives to alleviate the space needs to satisfy this demand. The authors apply freight/service 
trip generation models to commercial districts in Troy and New York City (NY, USA) to estimate the space requirements to satisfy parking demand. The scenario-based analysis of freight demand management initiatives (i.e., off-hour deliveries, staggered delivery times and receiver-led consolidation) shows that these initiatives can reduce parking space needs by 30 to $80 \%$. This research shows the importance of quantifying parking demand both in number of deliveries and duration to plan parking supply accordingly; and highlights the potential of freight demand management initiatives to alleviate parking space needs.

Pitera et al. [13] study the conflicts between cyclists and freight deliveries in Trondheim, Norway, and discuss the importance of including freight in the urban planning process. In their study, the authors first assess safety conditions via video recordings to identify risk areas where there is interaction between cyclists and freight deliveries, and then map the planning process for decisions involving freight facilities and their surroundings. The results show that most of the risk situations involved turning maneuvers of trucks before or after delivering goods. In terms of planning the results reveal limited discussion of freight operations during the planning, design and construction of buildings which can be partly explained by the lack of a person in charge of freight issues within governing authorities.

Aditjandra and Zunder [1] explore the importance of procurement policy in a University in Newcastle, England. The authors use purchasing data, interviews with the purchasing manager and data from a survey sent to the University staff to analyze the goods orders from University staff. The authors propose a model to estimate the frequency of orders per member of staff based on the individual characteristics and the type of goods purchased. The authors find that there are potential improvements to the sustainability of deliveries by influencing the procurement process. In particular, training specific staff that with responsibility for a large share of deliveries could lead to a better urban freight coordination and more sustainable practices. The authors highlight the importance of involving freight receivers and analyze the determinants of freight demand when aiming at accommodating freight in city planning.

\section{Planning for efficient metropolitan freight systems}

Palacios-Argüello et al. [12] propose a method to assess the economic and environmental performance of food distribution schemes for public school canteens in Lyon, France. The results reveal the importance of planning the logistics distribution system in a way that both reduces the negative impacts of food distribution and is economically feasible. The authors show the value of developing decision support tools to assess the environmental and economic implications of having different structures of food distribution systems (e.g., location and demand assignment). The resulting performance indicators can be used by public authorities in charge of selecting the logistics operator serving the public-school canteens.

Gonzalez-Calderon et al. [10] present the results of a multi-layer and multi-actor data collection to analyze the freight patterns in the Metropolitan Area of Medellin, Colombia. The analysis was based on surveys applied to receivers, suppliers and truck drivers. The results provide an overview of the freight moved across and within the city. The results provide insight to the public sector to design efficient policies that consider the scale of freight activity in the city as well as the types of vehicles used to transport it. Based on the freight data collected in this study and its results, the local government decided to start using the freight information to analyze projects, programs and policies to improve freight transportation system in the Medellin metropolitan area.

Fossheim and Andersen [9] compare planning practices for sustainable urban logistics between Scandinavia and the UK. The authors conduct a systematic literature review to analyze the inclusion of freight issues into city plans and find that UK cities include freight in their plan more often than Scandinavian cities. The results show that a number of plans are focused on the regional scope, which reduces the focus on the urban perspective and emphasize heavy goods vehicles that require a different policy approach. The authors also found an overall lack of assessment of the policy measures proposed in the plans.

\section{Planning for freight innovations}

Buldeo Rai et al. [4] propose a definition for crowd logistics and study the sustainability implications of using crowd logistics for urban freight transport via a systematic literature review and set of interviews with logistics practitioners. The authors found several attributes to differentiate types of crowd logistics concepts and analyzed the influence of these characteristics on sustainability. The results from this study can be used by policy-makers to design policy that considers the emerging sharing economy for freight.

Arnold et al. [3] study the implications of alternative delivery points for e-commerce deliveries. The authors use a simulation to assess the potential environmental and economic improvements of using delivery points and cargo bikes for B2C e-commerce distribution in Antwerp, Belgium. The results show that operational costs for companies can be reduced if customers pick-up their deliveries at pick-up points, but this will also lead to increasing external costs. The latter can be reduced if companies are willing to accept higher operational costs 
and implement a cargo bike-based distribution system. The authors conclude that a larger network of pick-up points can benefit society at large, but its implementation requires collaboration between multiple logistics operators and the involvement of the public sector which is clearly challenging.

\section{Involving freight stakeholders in planning}

Le Pira et al. [11] propose a decision-support procedure to foster stakeholder involvement and acceptability of urban freight transport policies. The authors introduce a model that integrates discrete choice and agent-based models to reproduce the interaction between urban freight stakeholders when jointly selecting a policy package. The method is adopted using data from Rome as a case study. The results from this research aim at supporting policy-makers to build consensus among stakeholders and support effective decision-making when accommodating urban freight policy into city planning.

The papers in this Topical Collection demonstrate the range of approaches that is required in order to gain greater insights into developments in urban freight. By providing these insights researchers are making a strong contribution to better planning for freight in cities. For example, the ability to compare cities and to look at how other cities address freight questions can provide both information and ideas for practitioners. Parking for freight vehicles to load and unload is a common issue facing cities - understanding ways to evaluate and measure this important activity can be valuable to city authorities. New trends such as crowd shipping also present great challenges in terms of possible regulation and also in how to assess the impacts of such a development. Within this TC all the papers contribute to our understanding of freight activity in the city and should also encourage further research on the themes identified in the papers. There are many possible future research directions. In terms of technology there have been many research studies considering autonomous cars at both an urban and long-distance scale. For freight transport, more attention has been focused on the longer distance movements and there has been considerable research about the platooning of trucks. There is certainly scope for more research on autonomous freight vehicles at the urban level. Turning to questions of the last mile then the rapid and continued growth in e-commerce raises many topics for further investigation. These include for example: (i) opportunities to make last mile logistics more efficient and sustainable by means of locker boxes and alternative delivery points (ii) how to achieve more coordination in delivery to the consumer either through pricing or by influencing consumer behavior about the timing of deliveries to the home (iii) the interaction between personal travel and goods movement - if people live in higher density residential areas and forego car ownership will there be a need for increased delivery trips? The list of topics could go on because the potential changes are certainly not clear at present.

This collection shows that it is possible to learn from the experiences in a wide variety of cities even though in some cases the particular initiative being investigated has a strong local context. With the widening recognition of the importance of urban freight and logistics activities we can be optimistic that there are many future research opportunities that will build on this collection and other recently published work.

Authors' contributions

All authors read and approved the final manuscript.

\section{Competing interests}

The authors declare that they have no competing interests.

\section{Publisher's Note}

Springer Nature remains neutral with regard to jurisdictional claims in published maps and institutional affiliations.

\section{Author details}

${ }^{1}$ Chalmers University of Technology, Gothenburg, Sweden. ${ }^{2}$ University of Gothenburg, Gothenburg, Sweden.

Received: 11 October 2018 Accepted: 11 October 2018

Published online: 29 November 2018

\section{References}

1. Aditjandra PT, Zunder TH (2017) Exploring the relationship between urban freight demand and the purchasing behaviour of a university. Eur Transp Res Rev. https://doi.org/10.1007/s12544-017-0273-5

2. Albergel A, Ségalou E, Routhier JL, and De Rham C (2006) Mise en place d'une méthodologie pour un bilan environnemental physique du transport de marchandises en ville. In Consommation-Emissions-Qualité de l'air, 88. LET-ARIA Technologies- System Consult

3. Arnold F, Cardenas I, Sörensen K, Dewulf W (2017) Simulation of B2C ecommerce distribution in Antwerp using cargo bikes and delivery points. Eur Transp Res Rev. https://doi.org/10.1007/s12544-017-0272-6

4. Buldeo Rai H, Verlinde S, Merckx J, Macharis C (2017) Crowd logistics: an opportunity for more sustainable urban freight transport? Eur Transp Res Rev. https://doi.org/10.1007/s12544-017-0256-6

5. Campbell S, Holguín-Veras J, Ramirez-Rios D, Gonzalez-Calderon C, Kalahasthi L, Wojtowicz J (2018) Freight and service parking needs and the role of demand management. Eur Transp Res Rev. https://doi.org/10.1186/ s12544-018-0309-5

6. Dablanc L (2007) Goods transport in large European cities: difficult to organize, difficult to modernize. Transp Res A Policy Pract 41:280-285

7. Dalla Chiara G, Cheah L (2018) Data stories from urban loading bays. Eur Transp Res Rev. https://doi.org/10.1007/s12544-017-0267-3

8. European Commission. 2013. 'Sustainable Urban Mobility Plans', Accessed 2018-09-01. https://ec.europa.eu/transport/themes/urban/urban_mobility/ urban_mobility_actions/sump_en

9. Fossheim K, Andersen J (2017) Plan for sustainable urban logistics comparing between Scandinavian and UK practices. Eur Transp Res Rev. https://doi.org/10.1007/s12544-017-0270-8

10. Gonzalez-Calderon C, Sanchez-Diaz I, Sarmiento-Ordosgoitia I, Holguín-Veras $\mathrm{J}$ (2018) Characterization and analysis of metropolitan freight patterns in Medellin, Colombia. Eur Transp Res Rev. https://doi.org/10.1186/s12544-0180290-z

11. Le Pira M, Marcucci E, Gatta V, Ignaccolo M, Inturri G, Pluchino A (2017) Towards a decision-support procedure to foster stakeholder involvement and acceptability of urban freight transport policies. Eur Transp Res Rev. https://doi.org/10.1007/s12544-017-0268-2 
12. Palacios-Argüello L, Gonzalez-Feliu J, Gondran N, Beadeig F (2018) Assessing the economic and environmental impacts of urban food systems for public school canteens: case study of great Lyon region. Eur Transp Res Rev. https://doi.org/10.1186/s12544-018-0306-8

13. Pitera K, Pokorny P, Kristensen T, Bjorgen A (2017) The complexity of planning for goods delivery in a shared urban space: a case study involving cyclists and trucks. Eur Transp Res Rev. https://doi.org/10.1007/s12544-0170262-8

Submit your manuscript to a SpringerOpen ${ }^{\odot}$ journal and benefit from:

- Convenient online submission

- Rigorous peer review

- Open access: articles freely available online

High visibility within the field

- Retaining the copyright to your article

Submit your next manuscript at $\boldsymbol{\nabla}$ springeropen.com 